\section{RADIO AIDS TO MARINE NAVIGATION}

$\mathrm{O}^{\mathrm{N}}$ NE of the earliest applications of radio wave transmission was the introduction of a service whereby ships could be informed of their position under conditions in which ordinary visual observations or dead reckoning were not very reliable. For many years past, radio direction-finding stations on shore have supplied bearings to ships making special signals for the purpose ; while many forms of direction-finder suitable for installation in ships have also been available, and could be used for observing the bearings of fixed radio beacons, which can easily be identified by the simple code signals emitted at regular intervals. During the past seven years, the growth and development of radio technique has been so rapid and so extensive that not only has a great deal of advance been made in the field of radio directionfinding as such, but also there has been devised and developed a number of alternative systems of using radio waves for fixing the position of a ship, whether it be in the open sea, near a coast or approaching a harbour. There are, in fact, so many possible systems of radio aids to marine navigation that it has become quite a difficult problem to decide which are the best or most appropriate for various applications. In order to reduce the number and variety of equipments to be carried by ships navigating in various parts of the world, it is clearly desirable that there should be some measure of international agreement on the matter.

It was with the view of providing scope for a full discussion of the value of these radio navigational aids, and of discovering to what extent they meet the requirements of the navigator and shipowner, that the Ministry of Transport organised an international meeting in London in May 1946 (see Nature, 157,$689 ; 1946$ ). The meeting was attended by some 120 delegates from twenty-three different countries, and a complete record of the proceedings of the meeting with its many lectures, demonstrations and visits has recently been compiled in two volumes by the Ministry of Transport and published by H.M. Stationery Office*.

The first volume provides a record of the proceedings of the conference with a full report of the discussions that followed the introductory lectures on the various systems, these lectures being given chiefly by the British naval officers and Government scientific workers who had been closely associated with the developments described.

The second volume contains the full text of the scientific and technical documents presented at the meeting, and comprises, in effect, a very full and up-todate handbook dealing with the whole problem of marine navigation by means of radio transmission and reception. After introductory chapters on the needs of the mariner for navigational aids, and on radio wave propagation as it affects them, the volume goes on to examine in detail all the radio navigational aids in existence or under development. One section deals with all aspects of radio direction finding, both from ship and from shore, and including the different types of radio beacon. Another section covers hyperbolic systems of navigation, including Loran, Gee,

- International Meeting on Radio Aids to Marine Navigation, May 1946. Vol. 1. Record of the Meeting and Demonstrations. 2s. 6d. net. Vol. 2. Radio Navigation : Radar and Position Fixing Systems for Use in Marine Navigation. 58. net. (London : H.M. Stationery Office, 1946.)
Decca and other names familiar to many in the Services during the War. A large section is devoted to marine radar in all its forms, as a ship-borne instrument, as a shore installation for harbour supervision and in the form of radar beacons. This section also includes a specification for a ship-borne radar set, drawn up by combining a knowledge of the user's needs with a knowledge of the technical possibilities. This should prove of great value to the radar manufacturer and the shipowner, because both will know that a set conforming to this specification will be in every way satisfactory.

The development of transmitting compasses for association with radio navigational aids is dealt with, as is also the question of the provision of special charts in order to facilitate the work of the navigator in using the various aids. In the later portions of the volume an appreciation, with considerable technical detail, is given of the various devices discussed, and an important chapter speculates on the probable future trends of development.

This whole volume, which is well illustrated with diagrams and photographs, is essentially technical, and it contains a large amount of information un. obtainable anywhere else. It will present many with their first picture of the far-reaching developments in radio navigational aids as a result of the War, and of the application of these developments to the safer and more efficient operation of ships at sea. It should prove of wide interest, and invaluable as a text-book to all who are in any way concerned with radio aids to navigation.

The publication of these two volumes is very opportune, and was in good time to pave the way for the continuation of the discussions at the recent international meeting in the United States of America.

\section{ROLE OF STARCH IN LIGHT- INDUCED STOMATAL MOVEMENT, AND A NEW REAGENT FOR STAINING STOMATAL STARCH}

\author{
BY DR. O. V. S. HEATH \\ Research Institute of Plant Physiology, \\ Imperial College of Science and Technology, \\ London
}

THE mechanism of the movement of stomatal guard cells in response to the stimulus of light, although under investigation for nearly a century, is still in doubt. The classical view ${ }^{1}$ that such movements are due to changes of turgor has received support from many workers, who have found by plasmolytic methods that with stomatal opening the osmotic pressure in the guard cells increases ${ }^{2-6}$. More recently, the possible collaboration of a "wall mechanism' in opening the stomata of Cyclamen and Tradescantia has been disproved ${ }^{7}$, so that a turgor mechanism alone must be concerned; but how the changes in turgor are produced is still uncertain. Mainly owing to the work of Lloyd ${ }^{8}$, Hagen ${ }^{\ominus}$, Loftfield ${ }^{10}$ and Sayre ${ }^{5}$ it is very generally accepted that they are due to hydrolysis or condensation of starch in the guard cells, probably brought about by enzyme action governed by $p H$ changes in response to light. A careful examination of these and other relevant 